Contreras, J;; Pujadas, J.J; Roca Girona, J. (coords.) (2012). Pels camins de l'etnografia: un homenatge a Joan Prat. Tarragona, Universitat Rovira i Virgili.

Diversos Autors (2012). El sofà blau. Migdiades amb el Joan Prat. Tarragona, DAFITS, ITA.

\title{
Un doble homenaje colectivo al amigo Joan Prat i Carós
}

\section{Fermin del Pino Díaz}

CSIC, Centro de Ciencias Humanas y Sociales, fermindelpino@gmail.com

Me alegra tener la oportunidad de sumarme al homenaje tributado al amigo Joan Prat, a quien conocí en el congreso de Segovia del año 1974 y con quien he compartido varios congresos posteriores, así como algunas complicidades historiográficas (todos nosotros en busca de ancestros nacionales respetables, y por medios historiográficos modernos). Eso me da la oportunidad de testimoniar la memoria que se le guarda fuera de su propio ámbito no solo por los colegas catalanes de su generación - lo que sería razonable-, sino también entre otros colectivos exteriores y anteriores (es decir, más veteranos). Ubicado en la segunda generación de antropólogos posterior a los fundadores, sin ser Joan Prat de los mayores, es verdad que ha tenido un rol articulador a nivel tanto de la comunidad catalana como de la española.

Yo lo puedo testimoniar en el campo de la historiografía antropológica, en la que me considero un hermano mayor suyo. Aunque se ha retirado joven de la carrera docente y se ha mantenido relativamente tranquilo en su pequeño departamento de Tarragona, eso no le ha impedido dejar una obra amplia y prestigiada, sin por ello perder la tranquilidad provinciana ni su talante irónico y dulcemente contestatario. Y sobre todo sin perder su talante conciliador por encima de cualquier coordenada antropológica. Aunque he visto muchos homenajes profesionales (no han sido tantos los que se han tributado a colegas antropólogos en España: Caro Baroja, Carmelo Lisón, Claudio Esteva, Julian Pitt-Rivers, Salvador Rodríguez...), no he encontrado en otros tanta unanimidad afectiva ni tanto acuerdo acerca de su capacidad innovadora entre colegas 
de diversos campos. Todo ello combinado con una complicidad personal y profesional que es raro encontrar.

Las dos obras de homenatge dedicadas a Joan son prácticamente simultáneas, aunque la segunda de ellas no lleva fecha (si bien se alude al primer homenaje como reciente y conectado). El primero de ellos se entiende que es un homenaje profesional, de antropólogos, mientras que el segundo sería de amigos, familiares y alumnos, todos ellos cargados de la misma emoción. Yo diría que el primer homenaje es menos doméstico (compuesto de 29 intervenciones, solo 9 de ellas se hacen en catalán, mientras que en el segundo escriben en esta lengua propia 48 de 61) y sus intervenciones son más largas, de una docena de páginas, no de un par. Es curioso que haya algunos que intervienen en ambos (9 de 61: Stanley Brandes, Lluís Calvo, Dolors Comas d’Argemir, Josep M. Comelles, Llorenç Prats, Joan J. Pujadas, Oriol Romaní, Jordi Roca y Jaume Vallverdú), casi siempre en otro tono más familiar y distendido, si bien la mayoría tratando los mismos temas profesionales. En el primer homenaje se conserva también el catalán para las partes "oficiales" (menos en el caso de Joan J. Pujadas cuando presenta el grupo segundo, tal vez respondiendo a la mayoría de participantes en castellano: 20/29). El mismo autor recurre al catalán en su participación dentro del segundo homenaje. En el primer homenaje se acompañan algunas fotos personales al inicio de cada apartado (fuera de las requeridas por dos artículos), mientras que en el segundo hay más fotos, algunas a color (magnífica la de escolano cantor de Montserrat). Tanto las cubiertas interiores iniciales y posteriores de este como el artículo de Jordi Roca están llenos de apuntes holográficos empleados por Joan en sus clases (con su letra cursiva tan clara). Nos llama la atención que este hábito manuscrito sea compatible con un afán de lectura voraz y universal y una preferencia por los panoramas esquemáticos y comparados.

Los participantes en el primer homenaje siguen perteneciendo mayoritariamente al entorno catalán o cercano (19/29: Jordi Roca, Enric Porqueres, Manuel Delgado, Josep M. Comelles, Jesús Contreras, Luis [así en el primero] Calvo, Llorenç Prats, Josefina Roma, Joan J. Pujadas, Joan Frigolé, Oriol Romaní, García Jorba, Dolors Comas d’Argemir y Jaume Vallverdú; y Josefa Cucó, de Valencia), pero se han sumado a él cuatro andaluces (Manuela Cantón, Salvador Rodríguez, Isidoro Moreno y Encarna Aguilar), cuatro de la academia madrileña (María Cátedra, Ricardo San Martín, Honorio Velasco y José Luis 
García), dos norteamericanos (William A. Christian Jr. y Stanley Brandes) y tres miembros individuales: Alberto Galván (Canarias), Teresa del Valle (de Euskal Herria) y Marcial Gondar (de Galicia).

En el caso del primer homenaje, la mayor parte se refiere a su propio trabajo, ligado a Joan, menos en algún caso excepcional (particularmente de William A. Christian, "Joan Prat, peregrino y hospitalero", pp. 111-117, traducido del inglés) que se dedica a darnos a conocer al personaje, con una sintonización extraordinaria, a partir de su decisión de dedicar al camino de Santiago su último trabajo de campo con motivo de su retiro académico. Jubilación, jubileo, júbilo... El homenajeado debe sentirse muy orgulloso de que uno de los mejores expertos internacionales en religión popular española haya dedicado su tiempo a examinar su talante etnográfico, y que decidiese, además, asistir personalmente al acto en que se le hizo entrega material del homenaje. Y, sobre todo, que haya señalado su identidad etnográfica en su talante de escuchar e involucrarse con los otros (sean informantes, peregrinos o discípulos).

Aparte de este caso particular, varios trabajos del primer homenaje han centrado alguna atención en Joan o se han referido a él más in extenso. En primer lugar, los propios editores, que han prologado cada una de las partes en que se decidió dividir el homenaje (Jordi Roca en "Antropologia de la religió i dels sistemes simbòlics"; Jesús Contreras en "D'etnografies i etnologies"; y Joan J. Pujadas en "Autobiografies, memòria i sistemes de representacions"). Nos recuerda Jordi su afición a los trabajos de campo y monografías de larga duración (idealmente de siete años, al modo judío, cuya cultura estudió atentamente; véase testimonio de Mario Sabán), así como su lealtad sostenida a las propias ideas (cosa que nos lo señala igualmente Llorenç Prats a propósito de la levedad científica del folklore o del incidente enojoso para Joan de los castellers ubicados en la plaza de toros de la Pobla de Montornès, que nos repite Stanley Brandes en los dos homenajes). Su amabilidad personal no está reñida con convicciones arraigadas y con cierto liderazgo sutil (iniciado ya en la Escolanía de Montserrat, según su compañero de fatigas Oriol Romaní).

En ese mismo contexto paradójico se ubica su interés por todas las manifestaciones religiosas marginales, por muy diversas que fuesen, por oponerse siempre a la inquisición secular traída por el mundo moderno. Inquisición que el trabajo de Manuel Delgado o el de Josefa Cucó equiparan al que se opone a los movimientos de contestación política, dotados asimismo de misticismo 
y compromiso personal altruista. Manuela Cantón, experta en movimientos pentecostales americanos (cuya capacidad reaccionaria e inhumana pudo percibir), es consciente también de su capacidad liberadora entre los gitanos andaluces, y, junto con Oscar Calavia y Joan Prat, muestra el lado represivo del Estado y la gran sociedad secular que los persigue. En esa misma línea del Estado inquisidor, detecta Marcial Gondar el peligro virtual que amenaza la sociedad global, que, a través de procesos de producción estandarizados y de modos de información virtuales, ha terminado por alejarnos de la realidad y someternos a una nueva inquisición despersonalizadora. Por el contrario, como Josefina Roma propone, la nueva literatura fantástica y el cine de evasión juvenil ( $\mathrm{La}$ guerra de las galaxias, El señor de los anillos, Harry Potter) no son más que una muestra del desencanto del mundo moderno global, que quiere regresar al pasado medieval (de la mano de filólogos como Tolkien y de antropólogos como Gerard Carlner o Margot Adler) o al futuro intergaláctico en busca de un mundo nuevo lleno de valores y significados interesantes.

Jesús Contreras nos recuerda el interés de ambos por ofrecer un panorama comparativo de la etnografía española, en un viaje iniciático en coche por la Península que era simultáneo al interés dominante de Joan por la tradición popular y folklórica catalana. Y Joan J. Pujadas, con Dolors Comas, nos informa de su apoyo inicial al proyecto de inventario biográfico adjunto al Arxiu d'Etnografia de Catalunya, del que se han nutrido muchos colaboradores y que ha alimentado un interés personal de Joan por las biografías personales (de líderes religiosos o de miembros de la profesión). A ello se dedica efectivamente uno de los apartados de este homenaje, con nueve participaciones que parecen no solo integradas, sino paradójicamente cargadas de futuro a partir de la memoria. Nos referimos, por ejemplo, al trabajo de Joan Frigolé cuando destaca, en su "Retorno a un hombre" (categoría weberiana recuperada por Wright Mills, aunque cuestionada por Bourdieu), el caso de la moral de hombre honrado exhibida por el obrero socialista contra todo otro cálculo político o económico.

En la misma línea, Josefa Cucó ("Històries de compromís al País Valencià") nos muestra el resultado de sus indagaciones biográficas sobre el caso de universitarios-obreros, ya detectado en la Francia de los años sesenta, que pasaron por unos estadios biográficos paralelos por la causa sindical y partidista durante el período franquista. Ya nos hemos referido al trabajo de Manuel Delgado (ubicado en el primer apartado religioso) sobre el compromiso político de los 
comunistas españoles bajo el franquismo como una "conversión" cuasi religiosa, que sería el mismo compromiso detectado por la profesora Cucó, al que habría que asociar ahora el trasvase eclesial al mundo sindical, paralelo al trasvase universitario-obrero detectado antes. Ese mismo trasvase eclesial-sindical se nos ofrece en el trabajo de Jaume Vallverdú sobre el movimiento de los campesinos sin tierra brasileños (1979-1984), apoyado por los teólogos de la liberación (el catalán Pere Casaldàliga al frente), que supieron convertir la lectura bíblica y la construcción popular de una cruz gigante de madera al borde de la carretera en una metáfora de su muerte y resurrección como movimiento popular triunfante de la política y los hacendados.

Nos queda la duda acerca de esta versión pentecostal de la teología de la liberación frente a otras opciones puramente laicas que la caracterizaron en otras zonas (frente a la tendencia bíblica, mayoritariamente protestante). Este tipo de lógica laica sería la opción elegida por Dolors Comas ("Mujeres con poder y su representación") cuando contrasta el poder real adquirido en la sociedad moderna con el poco reconocimiento que conceden al hecho los mass media (como se sabe, nada proclives a emitir visiones nuevas de la realidad, al tiempo que las promociona con la simple muestra de sucesos externos a la propia sociedad). Tal vez por esta constatación, la antropóloga Dolors eligió como carrera la representación política en Tarragona y en el Parlament catalán, donde se ocupa normalmente del área de los mass media. Un caso de compatibilidad disciplinar en cierto modo equiparable sería el de Teresa del Valle, reconocida igualmente en los temas de memoria y biografía de Joan Prat, cuando usa su esquema de la memoria mítica (no la individual o colectiva) para entender no solamente sus recuerdos hogareños evocados por el pan o los olores de la labranza, sino su estudio del nuevo ritual karriko que un grupo abertzale usó para asociar la lengua vasca al hombre paleolítico (conservado en las cuevas estudiadas por el folklorista Barandiarán y el antropólogo Aranzadi, maestros de Caro Baroja).

Si nos referimos a otros apartados como la etnografía o la antropología de la religión, no encontramos la misma integración en el homenaje, lo que da lugar a trabajos más o menos monográficos. Este sería el caso de María Cátedra, con su estudio comparado de las fiestas onomásticas de ciudades como Ávila o Évora, que no solo discutieron por sus reliquias o patrones fundadores, sino por sus antigüedades romanas (lo que constituyó un debate renacentista extendido a Andalucía y Aragón, en particular la zona de antigua influencia morisca, que 
merecería algún día la atención de un antropólogo). O el caso de Salvador Rodríguez, relativo a la devoción andaluza hacia la virginidad mariana (con la que merecería alguna vez cotejar el desborde sexual entrevisto por Joan, Romaní y Comelles en sus varias visitas al Rocío). La muestra que nos ofrece Comelles de ellas insiste más en su propia biografía como fotógrafo que en el contraste de las fiestas andaluzas y catalanas (de lo que dio una muestra en el homenaje a Salvador), y lo mismo ocurre en el segundo homenaje que Comelles dedica a ubicarnos en su "rito de paso" etnográfico con Joan Prat. No quiero dejar de referirme a la riqueza de sus impresiones personales, a pesar de su catalán medio poético y lleno de sobreentendidos, pero sin él nos perderíamos mucho de la intrahistoria etnográfica de la institución URV. Enric Porqueres nos introduce en el laberinto ontológico de la nueva antropología parisina alrededor del parentesco moderno europeo, y Alberto Galván nos invita a sumergirnos en el misterio insondable de la herencia femenina del cargo de brujo en la sociedad cubana tradicional, que nos recuerda la rica etnografía cubana heredada del mallorquín Fernando Ortiz (educado antes en ciencia criminológica en el Madrid de la Institución Libre de Enseñanza).

En el apartado etnográfico también se nos ofrecen estudios monográficos aislados. Encarna Aguilar nos invita a seguir el interés teórico del campesinado, mezclando las tradiciones etnográficas de los sesenta con la de la sociología rural. Sabido es el carácter compensatorio del campesinado ante la pérdida del objeto tradicional de la antropología clásica, por lo que relacionamos este planteamiento con el excelente "estado de la cuestión” ofrecido por José Luis García sobre la minería asturiana decadente, que el Estado español pretende suprimir por falta de mercado. Para ello, dedicó en los años noventa dinero a prejubilaciones con cursos sobre la minería tradicional, que los beneficiarios desprecian porque la supuesta cultura minera (reivindicada por los obreros en paro) es un "constructo" de poco más de un siglo que no permite una verdadera "reutilización patrimonial". La misma precaución nos pidió nuestro amigo J.L.G. en otros textos previos sobre el supuesto parentesco preferente de la sociedad asturiana, que no por ser declarado por la propia sociedad deja de ser un constructo. Los profesores Lluís Calvo y Llorenç Prats nos ofrecen panoramas históricoetnográficos de Cataluña, uno insistiendo en su cientificidad (importada del extranjero, principalmente de Alemania) y otro en su inevitable componente 
nacionalista, que el debate con Joan dejó al descubierto, a pesar del "compromiso" nacional que Llorenç confiesa haber tenido con el folklore catalán.

Otro debate histórico-etnográfico es sostenido en este apartado etnográfico por el profesor Moreno contra un texto inaugural ofrecido por Stanley Brandes en el reciente congreso de León sobre los orígenes franquistas de la antropología social española, nada menos. Reclamaría mucho espacio esta discusión, mal planteada por su primer autor; aunque tal vez no haya sido el mejor homenaje a Joan, la verdad es que la osadía historiográfica de nuestro amigo californiano merecía un correctivo. No solo se olvidaba del sesgo antifranquista de la escuela del Dr. Esteva y de la tradición republicana a que obedecía, sino que no distinguía entre los varios estudiosos extranjeros llegados a España en esta época franquista, algunos de los cuales estaban interesados en las clases sociales y en la política (Kenny, Arguedas o Susan Tax). La antropología cultural que deriva de su maestro G. Foster (famoso autor de la curiosa "teoría del bien limitado" o de la "cultura de conquista") le lleva a interesarse en rasgos supuestamente característicos de una sociedad, más que en la propia sociedad. Por su parte, Stanley nos ofrece en el primer homenaje sus dudas sobre el carácter hispano de la afición a los toros (en decadencia verificada por el autor), por oposición a otras imágenes "totémicas" de otras regiones españolas. Y en el segundo homenaje nos hace una historia de sus relaciones con Joan ("Joan y yo") que tal vez nos revele tanto su sincera amistad como alguna distancia personal.

No quisiera olvidarme del magnífico fresco ofrecido por Honorio Velasco sobre la feria de ganado en el área de Salamanca, centrando la atención en su ritual para establecer el precio y su retórica (llena de gestos y sentencias). Tal vez se trata de un trabajo autónomo, dada su minuciosidad y extensión, y quiero llamar la atención sobre sus paradojas (que el mantenimiento del precio sea referido como "tener palabra", clave para establecer el contrato entre comprador $y$ vendedor, $y$ que los expertos en el precio sean precisamente los "tratantes" $y$, sin embargo, sean ellos quienes dominen la retórica de la venta de ganado). Al lado de este, Ricardo San Martín nos ofrece sus reflexiones personales sobre la fiesta y los homenajes, y Juan M. García Orba sus impresiones sobre la importancia de la lectura a partir de un personaje popular de origen obrero del que no sabemos sino la inicial de su nombre (D.). No quisiera olvidarme de Oriol Romaní, miembro principal del grupo antropológico de la URV y siempre cercano a Joan (antes en Montserrat y en la Facultad), que dedicó su atención al 
mundo de las drogas, para afirmar desde la biografía de los drogodependientes lo mismo que Joan sostenía de los inocentes "sectarios" estigmatizados por la gran sociedad: que el grado de variedad de la dependencia merece ser tenida en cuenta de acuerdo a la realidad y no a las categorizaciones de la sociedad global. Como se ve, la riqueza de planteamientos a que ha dado lugar la rica personalidad de Joan Prat, sea en proyectos coordinados o libremente, nos revela la riqueza del personaje que estamos homenajeando. La personalidad de un autor se puede medir por la memoria que los amigos guardan de él y no solamente por sus propios recuerdos y escritos. 